\title{
COMPETITIVIDADE DO AÇÚCAR BRASILEIRO NO MERCADO INTERNACIONAL ${ }^{1}$
}

\author{
Luiz Carlos Dias ${ }^{2}$ \\ Giane Maria Gibbert ${ }^{3}$ \\ Pery Francisco Assis Shikida
}

Resumo - Este trabalho objetivou, por meio de um conjunto de indicadores, avaliar a competitividade do açúcar brasileiro no comércio internacional. $\mathrm{O}$ indicador marketshare evidenciou sua significativa importância, considerando que o Brasil foi responsável por 40,61\% do açúcar comercializado no mercado internacional em 2005. Em se tratando de competitividade frente a outros países e outros produtos, o indicador vantagem relativa na exportação também revela a vantagem competitiva do açúcar brasileiro. No que se refere à participação do açúcar no total das exportações brasileiras, o crescimento também é substancial, tendo aumentado sua representatividade em $95 \%$ no período analisado. A participação do saldo comercial do açúcar no PIB agrícola brasileiro também foi crescente no período analisado, considerando que em 1994 o açúcar representava menos de 1\% do PIB agrícola e chegou a representar 3,53\% em 2002. Esses dados ratificam a importância do açúcar brasileiro na geração de divisas e destacam sua crescente vantagem competitiva perante os demais países produtores e exportadores.

Palavras-chave: competitividade, açúcar e exportações.

\section{Introdução}

A literatura registra que a vulnerabilidade externa sempre foi a maior fragilidade da economia brasileira. A Comissão Econômica para a América Latina e Caribe (CEPAL), já na década de 1940, diagnosticou que a principal causa das dificuldades da América Latina, no setor externo, era que a entrada de divisas dependia das exportações de poucos produtos primários (Prebisch, 1949).

Os autores são gratos aos pareceristas desta Revista pelas profícuas sugestões e comentários.

2 Mestrando em Desenvolvimento Regional e Agronegócio pela UNIOESTE. E-mail: 1carlos-dias@ bol.com.br Mestranda em Desenvolvimento Regional e Agronegócio pela UNIOESTE. E-mail: gianemg@ bol.com.br

4 Professor Associado do Curso de Ciências Econômicas e do Programa de Mestrado em Desenvolvimento Regional e Agronegócio da UNIOESTE. E-mail: pfashiki@unioeste.br 
No Brasil, atualmente, os produtos agrícolas constituem alguns dos principais produtos de exportação e contribuem expressivamente para a provisão de divisas. A cana-de-açúcar é a segunda cultura em termos de valor de exportação, atingindo em torno de $12 \%$ das exportações agropecuárias nacionais. Na safra 2005/2006, o Brasil estima exportar 18,8 mil toneladas de açúcar, indicador que situa a agroindústria canavieira como a atividade do agronegócio que mais cresceu no Brasil em 2005 (Mendonça, 2006).

Na safra 2004/2005, o agronegócio canavieiro movimentou cerca de R \$ 40 bilhões, com faturamentos diretos e indiretos, o que corresponde a aproximadamente $2,35 \%$ do PIB nacional, além de ser um dos setores que mais empregam no País, com a geração de 3,6 milhões de empregos diretos e indiretos, e congregar mais de 72.000 agricultores. Outro indicador de sua importância econômica é a geração de impostos, tendo recolhido mais de $\mathrm{R} \$ 12$ bilhões aos cofres públicos no mesmo período (Gerchmann, 2005; Unica, 2006; Procana, 2006).

Conforme a Companhia Nacional de Abastecimento (Conab, 2006), a produção nacional da safra de cana-de-açúcar em 2005/06 fechou em 436,8 milhões de toneladas, representando crescimento de $5,1 \%$ em relação à safra de 2004/05. Esse aumento deve-se ao comportamento positivo nos preços do álcool e do açúcar e às boas condições climáticas. Esses dados ratificam o Brasil como maior produtor mundial de canade-açúcar e maior produtor e exportador de açúcar.

O interesse em analisar a agroindústria canavieira está relacionado ao cenário de expansão da cultura de cana-de-açúcar no Brasil, bem como a um cenário de forte crescimento das exportações para as próximas safras. Nesse sentido, este trabalho teve por objetivo analisar, por meio de um conjunto de indicadores, a competitividade do açúcar no mercado internacional a partir do ano de 1990, década caracterizada pela ruptura do padrão de desenvolvimento vigente até então, com mudanças profundas no regime de comércio (liberalização comercial), regime cambial, extinção do Instituto do Açúcar e do Álcool (IAA) e estabilização da economia. 
Este trabalho é composto de seis partes, incluindo esta introdução. $\mathrm{Na}$ segunda seção são apresentadas conceituações de competitividade. $\mathrm{Na}$ terceira seção é feita uma breve revisão de literatura sobre a evolução da competitividade do açúcar brasileiro. Na quarta seção é apresentada a metodologia utilizada na obtenção dos indicadores e avaliação da competitividade do açúcar produzido a partir da cana-de-açúcar no Brasil. Já os resultados e discussão são apresentados na quinta seção, e na última seguem as considerações finais.

\section{Conceituação de competitividade ${ }^{5}$}

Para Kupfer (1993), a competitividade é expressa pela participação no mercado (market-share) alcançado no comércio internacional total do produto, ou seja, numa definição bem simples, a competitividade é associada ao desempenho das exportações. Trata-se de um conceito expost, que avalia a competitividade através de seus efeitos sobre o comércio externo. Dessa forma, considera-se competitivo quem amplia sua participação no comércio internacional. Além de ser quase intuitivo, a vantagem desse conceito está na facilidade de construção de indicadores, argumento utilizado, por exemplo, por Gonçalves (1987) na análise das exportações brasileiras. É ainda o conceito mais amplo de competitividade, abrangendo não só as condições de produção, como todos os fatores que inibem ou ampliam as exportações. Assim, ao analisar a competitividade de um país, devem-se considerar também: as políticas cambial e comercial, a eficiência dos canais de comercialização e dos sistemas de financiamento, os acordos internacionais (entre países ou empresas), as estratégias de firmas transnacionais, entre outros.

\footnotetext{
Não é objetivo deste estudo detalhar os principais conceitos de competitividade existentes na literatura econômica. Não obstante, Silva (2004) apresenta uma revisão bibliográfica extensa e qualitativa sobre as fontes determinantes da competitividade. Para mais considerações a respeito, ver o autor supracitado.
} 
Complementando, Pinheiro et al. (1992, p. 3) afirmam que:

A competitividade das exportações depende de uma diversidade de fatores: da tecnologia disponivel e da eficiência com que é utilizada, dos preços domésticos dos insumos de produção, da taxa de câmbio e das taxas de paridade entre os parceiros comerciais do Brasil, da distância dos países competidores aos mercados de exportação brasileiros, dos custos portuários e de transporte, da estrutura de incentivos e subsídios à exportação no Brasil e nos países competidores, das barreiras tarifárias e não tarifárias no país importador, da qualidade e da imagem do produto, do tipo de financiamento à produção e à comercialização, gastos dos consumidores, etc.

Para Haguenauer (1989), a competitividade pode ser definida como a capacidade de uma indústria, setor ou país de produzir mercadorias com padrões de qualidade específicos, requeridos por determinados mercados, utilizando recursos em níveis iguais ou inferiores aos que prevalecem em indústrias semelhantes no resto do mundo, durante certo período de tempo. Com base nessa autora, o conceito de competitividade das exportações pode ser entendido a partir de três visões diferentes: a visão desempenho, a visão macro e a visão da eficiência.

A visão desempenho avalia a competitividade das exportações no mercado internacional. Quanto maior a participação do produto no mercado internacional, mais competitivas serão as exportações do país com relação a esse determinado produto. $\mathrm{O}$ indicador de competitividade, neste caso, é o modelo market-share.

$\mathrm{O}$ aspecto macro avalia a competitividade das exportações levando em conta decisões políticas, as quais, segundo Pinheiro e Horta (1992), são de grande relevância para o resultado. As variáveis de política econômica, 
principalmente a cambial e fiscal, podem ser usadas como mecanismos de aumento da competitividade das exportações. Por fim, a visão eficiência associa a competitividade das exportações à capacidade de um país em produzir bens com níveis de eficiência e qualidade superiores aos dos seus competidores no mercado. Custos e produtividade são indicadores de eficiência que explicam em parte a competitividade, pois ela não pode ser entendida como uma característica intrínseca de um produto ou de uma empresa.

Quanto às cadeias produtivas agropecuárias, o conceito de competitividade pode ser derivado da definição estabelecida por Porter (1991). Para esse autor, as empresas em geral podem adotar três tipos de estratégias competitivas: de liderança em custos, de diferenciação e de foco. A primeira visa obter vantagens competitivas pela oferta de produtos e serviços (em geral padronizados) a custos mais baixos do que os dos concorrentes. A segunda busca alcançar vantagens pela introdução de um ou mais elementos de diferenciação nos produtos e serviços que justifiquem preços mais elevados. E o terceiro tipo de estratégia objetiva obter vantagens competitivas ou pela oferta de produtos e serviços com menores custos, ou pela diferenciação deles, mas em um segmento de mercado mais localizado ou restrito.

Para o caso de cadeias produtivas de commodities, em face de nãodiferenciação do produto final, a competitividade é principalmente estabelecida por baixos custos de produção, que permite lucratividade para a cadeia produtiva mesmo quando os preços dos produtos são baixos. Isso significa uma eficiência produtiva maior ao longo de toda a cadeia produtiva. Nesse sentido, há consenso que o Brasil possui o menor custo mundial de produção de açúcar, conforme destaca a Tabela 1. 
Tabela 1 - Custo médio de produção de açúcar por país em US\$/t

\begin{tabular}{cc}
\hline País & Custo de médio de produção US\$/t \\
\hline Brasil (Centro-Sul) & 180 \\
África do Sul & 250 \\
Austrália & 270 \\
Tailândia & 310 \\
\hline
\end{tabular}

Fonte: Elaborado pelos autores a partir de Alves (2002) e Unica (2006).

É importante evidenciar que a competitividade do Brasil no mercado internacional de açúcar é devida, em grande parte, ao baixo custo de produção da cana-de-açúcar. No entanto, a produtividade média não é a melhor do mundo. Segundo Farina e Zylberstajn (1998), a produtividade média no Brasil é de 74 t/ha, enquanto a Austrália atinge a produtividade média de 89 t/ha. Literaturas mais recentes também confirmam essas médias (Moraes e Shikida, 2002; Paulillo et al., 2006).

No entanto, existem alguns pontos que interferem na competitividade da cadeia produtiva, como os custos dos fretes e custos portuários, os quais podem ser minimizados pelos investimentos em infra-estrutura. Por se tratar de commodity agrícola, esses custos têm forte impacto nos custos finais; para reduzi-los, alguns usineiros estão optando por construir terminais portuários privativos (Castro, 1996; FIESP/CIESP, 2001; ALCOPAR, 2006).

Não obstante os progressos realizados, a logística de transporte ainda é onerosa no Brasil, residindo aí uma desvantagem competitiva. A produção brasileira de açúcar é transportada em boa parte por meio de rodovias, cujo custo é reconhecidamente elevado, o que faz com que o País tenha custos de transporte elevados vis-à-vis seus concorrentes. O Gráfico 1 mostra uma comparação entre o Brasil e outros países no tocante à participação do modal rodoviário na matriz de transportes. 


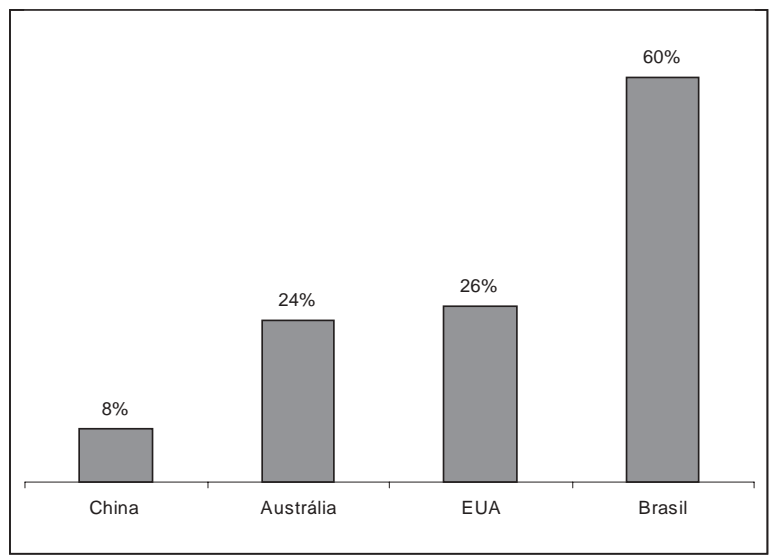

Gráfico 1 - Participação do modal rodoviário na matriz de transportes: comparação entre Brasil e outros países.

Fonte: Nazario, 2000.

Outra desvantagem competitiva do Brasil está nos serviços portuários, porquanto, apesar das melhorias resultantes dos investimentos realizados nos últimos anos, os custos portuários ainda são altos. Apenas para destacar, o custo dos portos de Vitória, Paranaguá, Rio de Janeiro e Santos (em US $\$ / \mathrm{m}^{3}$ embarcado) é de, respectivamente, US\$20, US\$20, US\$15 e US\$25; o custo do porto de Rotterdam é de US\$4,7.

Hijjar e Alexim (2006) salientam que os custos portuários também são afetados pelos problemas de acesso rodoviário. Quando o acesso aos portos não é eficiente, toda a operação de transporte da carga acaba sendo comprometida, pois os gargalos enfrentados na chegada ao porto promovem atrasos, aumentando o custo logístico total. 


\section{Breve revisão da literatura}

O mercado exportador de açúcar brasileiro tem sido estudado sob vários enfoques. Dos trabalhos existentes na literatura, podem-se citar como mais relevantes: Barros (1975) e Reis e Crespo (1998), que estudaram as exportações por meio de uma análise econométrica; Carvalho e Brandt (1987), os quais avaliaram os impactos da política de estabilização de preços nas exportações; Stalder e Burnquist (1997), que analisaram a elasticidade das exportações; Burnquist e Stalder (1999), que observaram o desempenho recente das exportações brasileiras de açúcar através do market-share; e Shikida e Bacha (1999), que discutiram os principais aspectos do mercado externo açucareiro e a posição brasileira nesse mercado.

A agroindústria canavieira brasileira viveu dois momentos diferenciados na década de 1990. O primeiro está relacionado à extinção do Instituto do Açúcar e do Álcool (IAA), no início da década, que alterou a dinâmica do mercado de açúcar; os produtores dessa commodity passaram a atuar em um ambiente competitivo e foram forçados a empregar mecanismos de mercado até então nunca utilizados, pois o preço era fixado pelo governo, de modo que a rentabilidade da atividade fosse, de certa forma, assegurada. As dificuldades relacionadas ao crédito estimularam os produtores a utilizar o mercado externo como forma de financiar a produção e aumentar a liquidez, sobretudo através de Adiantamentos sobre os Contratos de Câmbio (ACC). No período pós-desregulamentação, tanto a produção como as exportações brasileiras de açúcar cresceram a taxas superiores às praticadas anteriormente (Moraes, 2000).

Ainda de acordo com Moraes (2000), o segundo momento está relacionado à mudança da política cambial brasileira, ocorrida em janeiro de 1999, quando foi extinto o chamado "regime de bandas cambiais", que determinava os limites de flutuação do preço da moeda estrangeira, adotando-se o regime de câmbio flexível. Essa política cambial foi acompanhada por uma progressiva desvalorização da moeda brasileira, 
que elevou a competitividade dos produtos nacionais exportáveis, favorecendo, entre outros, o setor exportador de açúcar.

Não obstante, o setor de açúcar continua sendo protegido por quotas tarifárias, subsídios agrícolas, salvaguardas especiais e outros mecanismos, que fazem com que a competitividade do açúcar brasileiro no comércio externo seja instável. A principal forma de proteção aos produtos agrícolas na União Européia são as Organizações Comuns de Mercado (OCM), que fixam regras para plantio, comercialização, preços, subsídios, estocagem e comércio exterior. No entanto, esses subsídios estão sendo paulatinamente reduzidos, conforme acordos realizados na Organização Mundial do Comércio (OMC), fazendo com que os indicadores brasileiros relacionados à exportação de açúcar evoluam positivamente (Unica, 2006).

No Brasil, a competitividade do setor não pode ser analisada de forma homogênea, pois o País comporta dois subsistemas regionais na produção de cana-de-açúcar, um no Centro/Sul e outro no Norte/Nordeste, sendo o primeiro mais competitivo e dinâmico que o segundo (Moraes e Shikida, 2002; Vian, 2003).

Esses dois sistemas permitem safras alternadas, conferindo ao Brasil a possibilidade de produzir e abastecer o mercado ao longo de todo o ano, pois as safras das duas regiões ocorrem em épocas distintas: de setembro a março no Centro-Sul e de maio a dezembro no Nordeste. As vantagens do subsistema produtor de cana-de-açúcar do Centro/Sul estão correlacionadas a uma região considerada como de melhores características edafoclimáticas existentes no mundo, parque industrial forte, base para pesquisa agropecuária tradicional e tradição na produção. As vantagens do Norte/Nordeste são: localização para atender ao mercado local de açúcar e álcool; e o acesso a cotas especiais de exportação, principalmente para o mercado norte-americano (Moraes e Shikida, 2002). 
Os índices de evolução da cana-de-açúcar no Brasil, quanto a produção, área colhida, rendimento médio e exportação, podem ser vistos na Tabela 2.

Tabela 2 - Índices de produção, área colhida e produtividade da canade-açúcar e exportação de açúcar no Brasil 1990-2004

\begin{tabular}{ccccc}
\hline Ano & $\begin{array}{c}\text { Produção } \\
\text { (t) }\end{array}$ & $\begin{array}{c}\text { Área colhida } \\
\text { (ha) }\end{array}$ & $\begin{array}{c}\text { Rendimento médio } \\
\text { (t/ha) }\end{array}$ & $\begin{array}{c}\text { Exportação } \\
\text { (US\$ milhões) }\end{array}$ \\
\hline 1990 & 100 & 100 & 100 & 100 \\
1991 & 99 & 99 & 101 & 83 \\
1992 & 103 & 98 & 105 & 112 \\
1993 & 93 & 90 & 103 & 148 \\
1994 & 111 & 102 & 109 & 186 \\
1995 & 116 & 107 & 108 & 359 \\
1996 & 121 & 111 & 109 & 301 \\
1997 & 126 & 113 & 112 & 331 \\
1998 & 131 & 117 & 113 & 363 \\
1999 & 127 & 115 & 111 & 358 \\
2000 & 124 & 112 & 110 & 224 \\
2001 & 131 & 116 & 113 & 427 \\
2002 & 139 & 119 & 116 & 394 \\
2003 & 151 & 126 & 120 & 402 \\
2004 & 158 & 132 & 120 & 495 \\
\hline
\end{tabular}

Fonte: IBGE, 2006

A partir da análise dos resultados obtidos por meio dos indicadores, percebe-se que o açúcar brasileiro também apresenta grande dependência com relação ao comércio externo. Em 1993 as exportações de açúcar haviam crescido $48 \%$ em comparação ao ano de 1990 , enquanto a produção e área colhida de cana-de-açúcar caíram no mesmo período e o rendimento médio cresceu apenas 3\%. A superioridade dos números no que se refere à exportação, em comparação com produção, área colhida e rendimento médio, é acompanhada em todos os anos analisados, tanto que as exportações cresceram praticamente cinco vezes no ano de 2004 em comparação a 1990, ao passo que a produção cresceu 58\%; a área colhida, 32\%; e o rendimento médio, $20 \%$. 
O crescimento da produção de cana-de-açúcar resultou do efeito conjunto do aumento da área cultivada, que é influenciada pelo comportamento dos preços do álcool e do açúcar e conseqüente melhora da rentabilidade dos produtores, e da produtividade, a qual foi favorecida positivamente pelos fatores edafoclimáticos (Paulillo et al., 2006).

O crescimento da área colhida é resultado da ocupação de áreas antes usadas pela pecuária e pelo plantio de grãos, visto que a soja e a pecuária vêm passando por um período de crise. $\mathrm{O}$ aumento da área colhida também reflete a sensibilidade da cana-de-açúcar aos preços. De acordo com Samora (2006), a área cultivada com cana-de-açúcar no Brasil deverá manter a sua média de crescimento dos últimos cinco anos, impulsionada pela boa demanda por açúcar e álcool, tanto no mercado interno como no externo. Dessa forma, a estimativa de crescimento da área cultivada é de pelo menos 7\% para 2007.

No tocante à produção de cana-de-açúcar no Brasil, o crescimento foi de $5,1 \%$ na safra 2005/06, segundo levantamento realizado pela Conab (2006), enquanto a safra mundial cresceu apenas 3,5\% em relação à safra anterior, devido à quebra da produção indiana (Agrianual, 2006). Com isso, a produção mundial fica abaixo do consumo, de forma que a tendência é de que os estoques mundiais diminuam e o preço se eleve.

No que se refere à produtividade da cana-de-açúcar ao longo desse período, é importante levar em consideração o melhoramento das técnicas de cultivo, principalmente no preparo da terra. O aumento da produtividade da cana-de-açúcar no Brasil foi decorrente de diversos fatores, podendo-se citar: desenvolvimento de novas variedades, mais ricas em sacarose; controle de pragas e doenças; melhor manejo do solo; sistema de colheita mais eficiente; e uso de insumos modernos (Paulillo et al., 2006). Camargo Neto (1996) ressalta que, além disso, existe estreita relação entre o cultivo mecânico de soqueiras de cana e a longevidade do ciclo da cultura, o que permite aumentar a produtividade média da cana e efetuar a aplicação conjunta de fertilizantes com herbicidas. Essa inclinação de aumento da produtividade pode ser observada no Gráfico 2. 


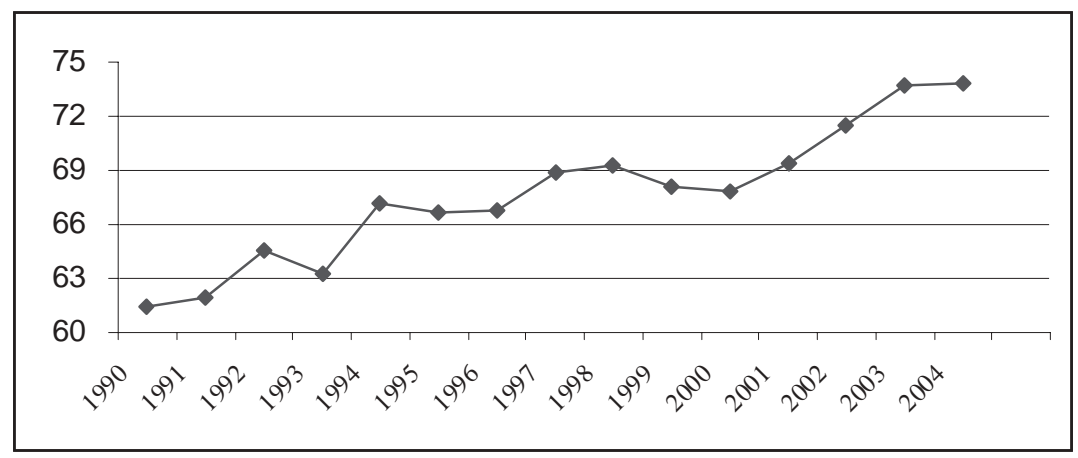

Gráfico 2 - Produtividade média brasileira da cana-de-açúcar - t/ha. Fonte: IBGE, 2006

Quanto às exportações, Alves e Bacchi (2004) apontam os principais fatores que impulsionaram o crescimento na década de 1990: a liberalização das exportações em julho de 1994, que encerrou o regime de quotas tarifárias, quando se taxava em $40 \%$ os volumes exportados superiores aos estabelecidos como quota; o aumento da demanda mundial, que se refletiu em condições favoráveis no mercado internacional; e a extinção de acordos especiais de comércio entre governos, que propiciou a entrada do Brasil em mercados fechados.

Com base nessas evidências, estima-se um crescimento de $70 \%$ na área plantada com cana-de-açúcar e de $100 \%$ na produção de cana-de-açúcar para os próximos 10 anos. Uma restrição no ritmo de crescimento mais forte do setor nos próximos anos está na relativa debilidade financeira de algumas usinas, mormente no Norte/Nordeste (Agrianual, 2006).

Nesse sentido, o governo brasileiro, por meio do Banco Nacional de Desenvolvimento Econômico e Social (BNDES), proporciona linhas de financiamento à exportação de bens e serviços em diversas modalidades. A modalidade de financiamento para exportação de açúcar mais utilizada pelo setor sucroalcooleiro é o pré-pagamento, feito entre uma trading e a usina produtora (Paulillo, 2006). 


\section{Indicadores utilizados}

Diversos autores, entre eles Reis et al. (1985) e Haguenauer (1989), têm sugerido que a competitividade não deve ser medida a partir de um único indicador, e sim por um conjunto de indicadores.

Os trabalhos de Carvalho et al. (2005) e Gasques e Conceição (2002) contribuíram para a definição dos indicadores de competitividade utilizados no presente trabalho. Ambos permitem avaliar a competitividade do açúcar brasileiro no comércio internacional a partir do ano de 1990. São eles:

a) Posição no mercado mundial - Market-share

$$
s_{k i}=\frac{X_{k i}}{X_{k c}} \cdot 100
$$

em que:

$$
\begin{array}{ll}
X=\text { valor das exportações; } & K=\text { açúcar; e } \\
I=\text { Brasil; } & W=\text { mundo. }
\end{array}
$$

Este indicador demonstra a participação percentual do país no mercado internacional de determinado produto. Como são expressos em porcentagem, os valores do indicador variam entre zero e cem. Quanto mais alto for esse valor, maior é a intensidade de participação do país no comércio internacional do produto selecionado. 
b) Vantagem relativa na exportação

vre $=\ln \left[\frac{X_{k i} / X_{k r}}{X_{m i} / X_{m r}}\right]$

em que:

$r=$ todos os países, exclusive $i ; e \quad m=$ todos os produtos, exclusive $k$.

Este indicador é utilizado para aferir a competitividade de um país em determinado produto, em comparação com os outros exportadores e outros produtos. Se $v r e_{k i}=0$, significa que a participação das exportações do produto $k$ no total das exportações do país $i$ é idêntica à observada, em média, nos demais países, caracterizando uma situação neutra, ou seja, o país não revela vantagem nem desvantagem no comércio do produto $\mathrm{k}$. Se $v r e_{\mathrm{ki}}>0$, o país $i$ revela vantagem na exportação de $k$ e, naturalmente, se vre $_{k i}<0$, desvantagem.

c) Participação de $k$ no total da exportação

$x_{k i}=\frac{X_{k i}}{X_{i}}{ }_{i} 100$

Este indicador demonstra a participação percentual das exportações de açúcar com relação ao total de exportações no país. Também é expresso em porcentagem e, portanto, os valores do indicador variam entre zero e cem. Quanto mais alto for esse valor, maior é a intensidade das exportações do produto com relação aos demais produtos exportados pelo país. 
d) Participação do saldo comercial de $k$ no PIB agrícola

$$
y_{k i}=\frac{\left(X_{k i}-M_{k i}\right)}{Y_{i}}{ }_{x} 100
$$

em que:

$Y=$ PIB agrícola; e $\quad M=$ valor da importação.

Este indicador mostra a importância relativa do saldo comercial de $k$ no PIB agrícola.

e) Participação do comércio de $k$ no comércio total dos produtos agrícolas

$$
q_{k i}=\frac{X_{k i}+M_{k i}}{X_{i}+M_{i}} x 100
$$

Este indicador mostra o peso relativo do produto $k$ no intercâmbio comercial agrícola do país.

\section{Resultados e Discussão}

Como se pode verificar na Tabela 3, o efeito conjunto do aumento da área cultivada e dos ganhos de produtividade da cana-de-açúcar elevou a participação brasileira no mercado externo de açúcar (market-share) de 4,94\% do valor das exportações mundiais em 1991 para 40,61\% em 
2005, representando uma taxa geométrica de crescimento de $13,84 \%{ }^{6}$

Tabela 3 - Indicadores da competitividade da exportação do açúcar brasileiro, no período 1991-2005

\begin{tabular}{ccc}
\hline Ano & Market-Share (\%) & $\begin{array}{c}\text { Vantagem relativa } \\
\text { na exportação (vre) }\end{array}$ \\
\hline 1991 & 4,94 & - \\
1992 & 8,01 & 2,21 \\
1993 & 9,26 & 2,57 \\
1994 & 13,43 & 2,77 \\
1995 & 15,90 & 3,48 \\
1996 & 15,39 & 3,23 \\
1997 & 20,98 & 3,50 \\
1998 & 24,62 & 3,91 \\
1999 & 27,14 & 4,40 \\
2000 & 20,23 & 3,47 \\
2001 & 27,68 & 4,16 \\
2002 & 30,21 & 4,36 \\
2003 & 33,34 & 4,36 \\
2004 & 38,70 & 4,81 \\
2005 & 40,61 & 4,26 \\
\hline $\mathrm{R}^{2 *}$ & $13,84 \%$ & $5,05 \%$ \\
\hline Taxa Geométrica Crescimento & $89,91 \%$ & $80,34 \%$ \\
\hline
\end{tabular}

* apresentam significância a 5\% de probabilidade.

Fonte: Dados da pesquisa (elaborado a partir de AGRIANUAL 2000 e 2006 e FUNCEX, 2006).

\footnotetext{
6 A estimativa da taxa geométrica de crescimento, calculada para todo o período, está de acordo com o método dos mínimos quadrados, em que:

$\mathrm{Y}_{\mathrm{n}}=\mathrm{Y}_{\mathrm{o}}(1+\mathrm{r})^{\mathrm{t}}$

Logaritmizando (1), tem-se:

$\operatorname{LnY}=\operatorname{Ln}\left[Y_{0}(1+r)^{t}\right]$

Aplicando as propriedades da multiplicação e potenciação da função logarítmica e simplificando (2), tem-se: $\operatorname{LnY}_{\mathrm{n}}=\operatorname{LnY}_{\mathrm{o}}+\mathrm{t} \operatorname{Ln}(1+\mathrm{r})$

Chamando $\operatorname{LnY}_{\mathrm{n}}$ de $\mathrm{Y}, \operatorname{LnY}_{\mathrm{o}}$ de B e $\operatorname{Ln}(1+\mathrm{r})$ de $\mathrm{M}$, tem-se a seguinte função linearizada:

$\mathrm{Y}=\mathrm{B}+\mathrm{Mt}$

Com os valores de t e $\mathrm{Y}$ faz-se uma regressão, obtendo-se o valor do coeficiente angular $\mathrm{M}=\mathrm{Ln}(1+\mathrm{r})$

Destarte, $(1+\mathrm{r})=\mathrm{e}^{\mathrm{M}}, \log \mathrm{o}, \mathrm{r}=\mathrm{e}^{\mathrm{M}}-1$

Nas taxas de crescimento seguem também os coeficientes de ajustamento ou determinação $\left(R^{2}\right)$ - que designa o poder explicativo de uma equação: quanto mais o $\mathrm{R}^{2}$ se aproximar de 1, maior será o seu poder explicativo; de igual modo, quanto mais o $\mathrm{R}^{2}$ se aproximar de 0 , menor será o seu poder explicativo. Para complementar o cálculo do $\mathrm{R}^{2}$ utiliza-se o teste " $\mathrm{t}$ " (em que se constrói um intervalo de confiança para observar se o valor alegado está ou não incluído nesse intervalo - neste trabalho, considera-se o nível de confiança de 95\%). Para mais considerações sobre o cálculo dessas taxas, ver: Hoffmann e Vieira (1987).
} 
Nesse contexto, a representatividade do açúcar brasileiro no mercado internacional tende a aumentar ainda mais, visto que a União Européia vem diminuindo suas exportações, devido à queda nos subsídios imposta pela Organização Mundial do Comércio (OMC); além disso, outros países exportadores estão destinando maior parte da cana-de-açúcar para produção de combustível em detrimento de açúcar.

O indicador vantagem relativa na exportação (vre) demonstra que o Brasil vem elevando sua competitividade na exportação de açúcar, quando comparado com outros países exportadores e outros produtos. Em 1992 o índice era de 2,21, porém os dados evidenciaram que este índice chegou a atingir 4,81 no ano de 2004, indicando forte tendência de aumento de produção e conseqüente exportação, demonstrando, dessa forma, que o Brasil tem sustentado elevada competitividade. Ademais, a evolução dessas estimativas, ao longo do tempo, dá a perspectiva de aumento da competitividade.

O Brasil tornou-se o maior exportador mundial de açúcar a partir da safra 1995/96, ultrapassando a Austrália, e continua sustentando essa posição. Analisando o Gráfico 3, percebe-se que as exportações mantiveram-se estáveis nos demais países que exportam o produto, exceto no Brasil, que apresentou crescimento expressivo. 


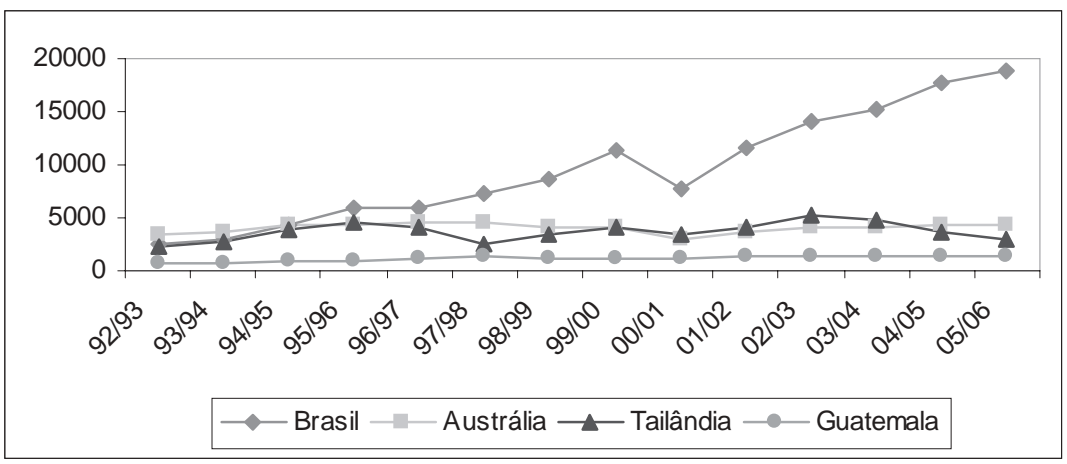

Gráfico 3 - Principais países exportadores de açúcar, em toneladas. Fonte: AGRIANUAL, 2000, 2006.

O aumento das receitas dos produtores de açúcar está relacionado ao aumento no preço médio pago pelo produto no mercado internacional. No Gráfico 4, pode-se observar que o açúcar atingiu em 2005 as maiores cotações desde 1992. Esse resultado é proveniente do desequílibrio entre oferta e procura, além da pressão pela demanda de álcool por parte do Brasil e da queda na oferta de açúcar por tradicionais países exportadores, como Tailândia, Paquistão e China. 


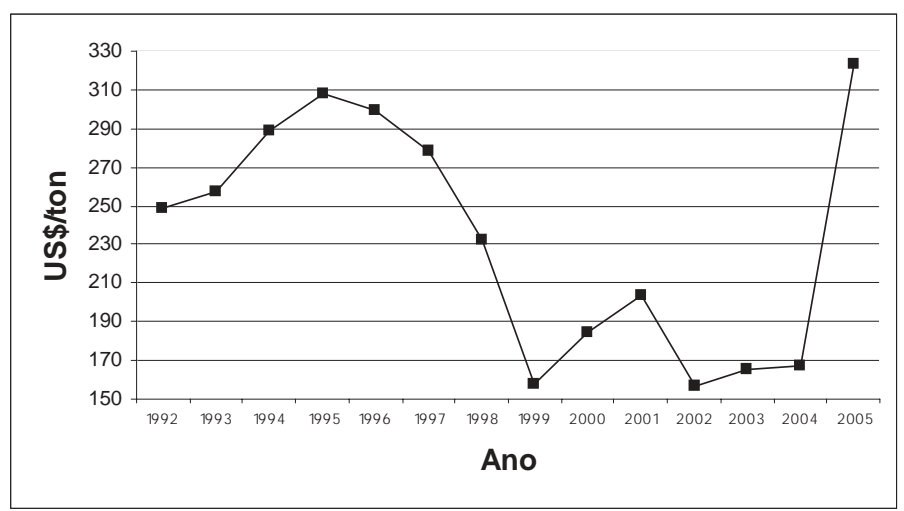

Gráfico 4 - Preço médio do açúcar - US\$/tonelada.

Fonte: SECEX, 2006.

Ainda no Gráfico 4, percebe-se que o setor sucroalcooleiro entra em crise, refletindo uma queda expressiva no preço do açúcar em meados de 1999. Essa crise ocorreu, sobretudo, devido a dois fatores: os preços do petróleo diminuíram, arrefecendo economicamente a utilização do álcool como combustível; e houve a crise financeira que atingiu os países asiáticos e a Rússia (maiores importadores mundiais de açúcar), reduzindo assim o consumo e gerando aumento dos estoques mundiais.

Os ganhos de competitividade do açúcar e sua importância crescente para a economia brasileira ficam mais evidentes quando se observa a participação do saldo comercial do açúcar no PIB agrícola $\left(y_{k i}\right)$. Até o ano de 1995 representava menos de $1 \%$, elevando sua participação para $3,53 \%$ em 2002 (pico) e retrocedendo a 2,34\% em 2005. Além disso, em 1990 a participação do açúcar no total das exportações brasileiras $\left(x_{k i}\right)$ era de 1,7\%, e em 1999 alcançou 3,98\%. A participação do comércio de açúcar no comércio total dos produtos agropecuários do País $\left(q_{k i}\right)$ segue a mesma tendência de crescimento de importância, com destaque para 
os anos de 1995 e 1999, que atingiram 7,35\% e 6,28\%, respectivamente, no comércio total dos produtos agropecuários, conforme demonstra a Tabela 4.

Tabela 4 - Indicadores da competitividade do açúcar brasileiro

\begin{tabular}{cccc}
\hline Ano & $\begin{array}{c}\text { Participação do saldo } \\
\text { comercial de açúcar } \\
\text { no PIB agrícola }(\%)\end{array}$ & $\begin{array}{c}\text { Participação do açúcar } \\
\text { no total das exportações } \\
\text { do país }(\%) x_{k i}\end{array}$ & $\begin{array}{c}\text { Participação do comércio de } \\
\text { açúcar no comércio total dos } \\
\text { produtos agropecuários do país } \\
(\%)\end{array}$ \\
\hline 1990 & - & 1,70 & 2,83 \\
1991 & - & 1,41 & 2,92 \\
1992 & - & 1,68 & 3,38 \\
1993 & - & 2,04 & 3,94 \\
1994 & 0,84 & 2,28 & 3,48 \\
1995 & 0,97 & 2,14 & 7,35 \\
1996 & 1,04 & 3,37 & 4,30 \\
1997 & 1,12 & 3,34 & 4,14 \\
1998 & 1,21 & 3,80 & 4,63 \\
1999 & 1,79 & 3,98 & 6,28 \\
2000 & 1,96 & 2,02 & 3,28 \\
2001 & 2,32 & 3,91 & 5,05 \\
2002 & 3,53 & 3,49 & 4,54 \\
2003 & 2,89 & 2,94 & 3,37 \\
2004 & 2,65 & 2,74 & 3,50 \\
2005 & 2,34 & 3,32 & 5,42 \\
\hline Taxa Geométrica & $13,11 \%$ & $5,10 \%$ & $1,95 \%$ \\
de Crescimento & $84,3 \%$ & $49,12 \%$ & $11,56 \%$ \\
\hline $\mathrm{R}^{2}$ & & & \\
\hline
\end{tabular}

* apresentam significância a 5\% de probabilidade.

Fonte: Dados da pesquisa (elaborado a partir de FUNCEX e IPEADATA, 2006).

Outro motivo de otimismo para os produtores de açúcar é que a China, país com a maior população mundial e com as maiores taxas de crescimento econômico das últimas duas décadas, ainda apresenta um consumo per capita muito baixo. Enquanto nos Estados Unidos e União Européia o consumo de açúcar é de $20 \mathrm{~kg}$ por habitante/ano, os chineses não passam de $7 \mathrm{~kg}$ por habitante/ano (Genestoux, 2000). 


\section{Considerações finais}

Este trabalho analisou a competitividade do açúcar brasileiro frente ao mercado externo e sua importância na geração de divisas. Isso posto, cabem alguns comentários pertinentes, à guisa da conclusão.

A importância do açúcar no total produzido pelo País, bem como no comércio externo brasileiro, ficou ainda mais evidente a partir de meados dos anos 90. Esse aumento de representatividade se deve, principalmente, aos preços internacionais do açúcar e à política energética adotada pelo governo brasileiro, que aqueceram o setor. Com a intenção de obter maior índice de lucratividade para seus produtos, as indústrias intensificaram o uso de novas tecnologias, tanto no cultivo da cana-deaçúcar como no processo de industrialização do açúcar. Essas mudanças foram motivadas após a desregulamentação dessa atividade econômica e fizeram com que o Brasil conquistasse a liderança em produção e exportação mundial desse produto. Não obstante, os custos de transportes e portuários são gargalos que devem ser superados para que a competitividade da agroindústria canavieira seja maximizada.

Com o indicador market-share, que demonstra a participação percentual do país no mercado internacional de determinado produto, foi possível visualizar a crescente importância do açúcar brasileiro no mercado externo, sendo ele responsável por 40,61\% do total mundial exportado em 2005. Essa importância é confirmada pelo indicador vantagem relativa na exportação (vre), que indica que o açúcar do Brasil é competitivo frente aos outros países e outros produtos, pois se o índice fosse zero caracterizaria uma situação neutra. O Brasil inicia o período analisado (1992) com vre $=2,21$ e chega a 2005 com vre $=4,26$, demonstrando também a crescente expansão nesse índice.

Outro dado revelado pelo trabalho é a crescente importância do açúcar no que se refere ao total exportado, já que esse índice em 1990 era de $1,7 \%$ e passou para $3,32 \%$ em 2005, propiciando uma taxa geométrica de crescimento de $5,1 \%$ na participação do valor exportado pelo Brasil. 
Quanto à participação do saldo comercial do açúcar no PIB agrícola, a variação da taxa geométrica de crescimento foi de 13,11\% entre 1994 e 2005 , enquanto a participação do comércio de açúcar no comércio total dos produtos agropecuários teve aumento de $11,56 \%$ no período de 1990 a 2005.

Em suma, os resultados ora apresentados valorizam a importância do açúcar brasileiro tanto no que se refere à contribuição desse setor para ampliação de divisas no cenário internacional (já que não se configura somente como um setor primário exportador, agregando valor aos produtos e gerando mais empregos e renda), como também demonstra importância e crescente vantagem frente aos países concorrentes.

A perspectiva de demanda mundial crescente por açúcar, influenciada diretamente pelo aumento do consumo mundial e pelas perspectivas de redução do produto em países que estão investindo na produção de álcool combustível em detrimento de incrementos na produção de alimentos, influencia diretamente a expansão da área plantada e, conseqüentemente, o aumento de produção de açúcar no Brasil.

\section{Referências}

AGRIANUAL. Anuário estatístico da agricultura brasileira. São Paulo: FNP/M\&S, 2000.

AGRIANUAL. Anuário estatístico da agricultura brasileira. São Paulo: FNP/M\&S, 2006.

ALVES, L. R. A. Transmissão de preços entre produtos do setor sucroalcooleiro do estado de São Paulo. Dissertação (Mestrado em Economia Aplicada) - Escola Superior de Agricultura Luiz de Queiroz, 2002. 
ALVES, L. R. A.; BACCHI, M. R. P. Oferta de exportação de açúcar do Brasil. Revista de Economia e Sociologia Rural, Brasília, v. 42, n. $1,2004$.

BARROS, W. J. de. Análise econométrica dos mercados interno e de exportação de açúcar. 1975. Dissertação (Mestrado) - Universidade Federal de Viçosa, Viçosa, MG.

BURNQUIST, H. L.; STALDER, S. H. G. de. Desempenho recente das exportações brasileiras de açúcar: uma abordagem de "market-share" constante. Revista de Economia e Sociologia Rural, Brasília, v.37, n.3, p. 69-90, jul.-set. 1999.

CAMARGO NETO, P. Açúcar, resistindo à liberalização. Agroanalysis, FVG, Rio de Janeiro, v.6, n. 1, p. 16-18, jan.1996.

CARVAlHO, F. C.; BRANDT, S. A. Avaliação da política de estabilização de preços no mercado de exportação de açúcar do Brasil. Revista de Economia Rural, Brasília, v.25, n.3, p.357-365, jul.-set. 1987.

CARVALHO, M. A. et al. Competitividade da soja e geração de divisas. Revista de Economia e Agronegócio, Viçosa, v. 3, n. 3, p. 301-321, 2005.

CASTRO, M. Exportações rendem US\$ 1,43 bi. Gazeta Mercantil. São Paulo. 12 dez 1996.

CONAB - Companhia Nacional de Abastecimento. Produção de cana cresce e safra se mantém histórica. Disponível em: http:// www.conab.gov.br/index.php?PAG=73\& NSN=401. Acesso em: 6.set.2006.

FARINA, E. M. M. Q.; ZYLBERSTAJN, D. Competitividade no agribusiness brasileiro. Relatório Final. IPEA/PENSA/USP. 1998. 
FIESP/CIESP. Ampliação da oferta de energia através da biomassa. Disponível em: <http://www.fiesp.com.br/download/ publicacoes_meio_ambiente/relatorio_dma.pdf> Acesso em: 5dez. 2006.

FUNCEX - Fundação Centro de Estudos do Comércio Exterior. Base de dados estatísticos. Disponível em: <http://www.funcex.com.br/ basesbd/> Acesso em: 7set.2006.

GASQUES, J. G.; CONCEIÇÃO, J. C. P. R. da. Indicadores de competitividade e de comércio exterior da agropecuária brasileira. Brasília: IPEA, 2002. (Texto para discussão n. ${ }^{\circ}$ 908).

GEIPOT - Empresa Brasileira de Planejamento de Transportes. Indicadores do setor transporte. Disponível em: <http:// w w w.geipot.gov.br/inidcadores internet/ inidcadores do setor trasnporte.htm> Acesso em: 14dez.2006

GENESTOUX, P. D. Tendências, desafios e perspectivas para a produção mundial de cana, açúcar e os mercados. Stab-Açúcar, Álcool e Subprodutos, Piracicaba, v. 18, n. 5, p. 36-44, maio/jun. 2000.

GERCHMANN, L. Uruguai estuda adoção de álcool. Folha de São Paulo. São Paulo, 5.abr. 2005.

GONÇALVES, R. Competitividade internacional, vantagem comparativa e empresas multinacionais: o caso das exportações brasileiras de manufaturados. Pesquisa e Planejamento Econômico, Rio de Janeiro, v. 17, n.2, 1987.

HAGUENAUER, L. Competitividade: conceitos e medidas. Uma resenha da bibliografia recente com ênfase no caso brasileiro. Rio de Janeiro: IEI/UFRJ, 1989. (Texto para discussão n. ${ }^{\circ} 211$ ).

HIJJAR, M. F.; ALEXIM, F. M. B. Avaliação do acesso aos terminais portuários e ferroviários de contêineres no Brasil. Disponível em: $<\underline{\mathrm{htt}}$ : // joom la.coppead.ufrj.br/port/ 
index.php?option=com docman\&task=cat view\&gid=56\&Itemid $=204>$ Acesso em: 14dez.2006.

HOFFMANN, R.; VIEIRA, S. Análise de regressão: uma introdução à econometria. 2. ed. São Paulo: Hucitec, 1987.

IBGE - Instituto Brasileiro de Geografia e Estatística. Levantamento Sistemático da Produção Agrícola. Disponível em: <http:// www.ibge.gov.br/home/estatistica/indicadores/ agropecuaria/lspa/ default.shtm> Acesso em: 7set.2006.

IPEADATA. Valor FOB das exportações por setor: açúcar. Disponível em: <http://www.ipeadata.gov.br/ipeaweb.dll/ ipeadata?23202015>

KUPFER, D. Padrões de concorrência e competitividade. Rio de Janeiro: IEI/UFRJ,1993. (Texto para discussão n. ${ }^{\circ}$ 265).

MDIC - Ministério do Desenvolvimento, Indústria e Comércio Exterior. Brasil: Exportações agropecuárias. <Disponível em: http:// aliceweb.desenvolvimento.gov.br/default.asp> Acesso em: 7 set.2006.

MENDONÇA, M. L. A OMC e os efeitos destrutivos da indústria da cana no Brasil. Disponível em: $<$ http://www.landaction.org/ display.php?article=397> Acesso em: 6set.2006.

MORAES, M.A.F.D. de. A desregulamentação do setor sucroalcooleiro do Brasil. Americana: Caminho Editorial, 2000.

MORAES, M. A. F. D. de; SHIKIDA, P. F. A. (Orgs.) Agroindústria canavieira no Brasil: evolução, desenvolvimento e desafios. São Paulo: Atlas, 2002.

NAZARIO, P. Intermodalidade: importância para a logística e estágio atual no Brasil. In: FLEURY, P.F.; WANKE,P.; FIGUEIREDO, K. Logística empresarial: a perspectiva brasileira. São Paulo: Atlas, 2000. 
PAULILlO, L. F. et al. Análise da competitividade das cadeias de agroenergia no Brasil. In: BUAINAN, A. M.; BATALHA, M. O. (Coord.) Análise da competitividade das cadeias agroindustriais brasileiras. São Carlos: DEP-UFSCAR/IE-UNICAMP, fev.2006.

PINHEIRO, A. C. et al. Indicadores de competitividade das exportações: resultados setoriais para o período 1980/88. Rio de Janeiro: IPEA, 1992. (Texto para discussão n. ${ }^{\circ} 257$ ).

PINHEIRO, A. C.; HORTA, M. H. A competitividade das exportações brasileiras 1980/88. Pesquisa e Planejamento Econômico, Rio de Janeiro, v. 22, n.3, p. 437-474, dez. 1992.

PORTER, M. E. Estratégia competitiva. Rio de Janeiro: Campus, 1991.

PREBISCH, R. O desenvolvimento econômico da América Latina e seus principais problemas. Revista Brasileira de Economia, Rio de Janeiro, p. 47-111, set. 1949.

PROCANA, Um mercado de R\$ 40 bilhões. Disponível em: <http:// www.jornalcana.com.br/Conteudo/Conheca\%200\%20Setor.asp> Acesso em: 6set.2006.

REIS, E. J. et al. Política cambial e exportações. Rio de Janeiro: IPEA, 1985.

REIS, J. N. P.; CRESPO, J. E. Q. Um modelo econométrico para as exportações de açúcar do Brasil. Agricultura em São Paulo, São Paulo, v.45, n.1, p.17-32, 1998.

SAMORA, R. Área de cana no Brasil crescerá ao menos $7 \%$ em 2007. Disponível em 〈http://br.news.yahoo.com/060802/5/17f 9 b.html $>$ Acesso em: 6set.2006. 
SECEX - Secretaria de Comércio Exterior. Exportação brasileria de açúcar. Disponível em: <http://www.agricultura.gov.br/pls/portal/docs/ PAGE/MAPA>Acesso em: 4out.2006.

SHIKIDA, P. F. A.; BACHA, C. J. C. . Alguns aspectos do mercado externo açucareiro e a inserção brasileira neste mercado. Revista Econômica do Nordeste, Fortaleza, v. 30, n. 3, p. 372-385, 1999.

SILVA, C. L. da. Competitividade e estratégias internacionais. Curitiba: Juruá, 2004.

STALDER, S. H. G.; BURNQUIST, H. L. Exportações de açúcar no Brasil: uma abordagem de elasticidade. In: CONGRESSO BRASILEIRO DE ECONOMIA E SOCIOLOGIA RURAL, 35, 1997, Natal. Anais. Brasília: SOBER, 1997.

UNICA - União da Agroindústria Canavieira de São Paulo. Liberalizando o comércio internacional de açúcar. Disponível em: $<$ www.unica.com.br/files/palestras/disc embaixador.

Doc> Acesso em: 6set.2006.

VIAN, C. E. de F. Agroindústria canavieira: estratégias competitivas e modernização. Campinas: Átomo, 2003. 
Abstract - The study objectifies, by means of a group of indicators, to evaluate the competitiveness of the Brazilian sugar in the international trade. The indicator marketshare evidenced its significant importance, considering that Brazil was responsible for $40,61 \%$ of the sugar commercialized in the international market in 2005. About the competitiveness front to other countries and other products, the indicator relative advantage in the export also discloses the advantage competitive of the Brazilian sugar. As for participation of the sugar in the total of the Brazilian exportations, the growth is substantial, having increased its representation in $95 \%$ in the analyzed period. The participation of the commercial balance of the sugar in the GIP Brazilian agricultural also was increasing in the analyzed period, considering that in 1994 the sugar represented less than $1 \%$ of the GIP agricultural and arrived to represent $3.53 \%$, in 2002. These data ratify the importance of the Brazilian sugar in the generation of income and detach its increasing competitive advantage before the too much producing and exporting countries.

Key-words: Competitiveness, sugar and exportations. 